\title{
The Absorption Performance of Ionic Liquids-PEG200 Complex Absorbent for VOCs
}

\author{
Wenlin Zhang, Jinping Luo, Tengfei Sun, Fengshou Yu * and Chunli Li \\ National Local Joint Engineering Laboratory for Energy Conservation of Chemical Process Integration and \\ Resources Utilization, School of Chemical Engineering and Technology, Hebei University of Technology, \\ Tianjin 300130, China; ctstzw1@163.com (W.Z.); luojpl@163.com (J.L.); ctstsuntengfei@163.com (T.S.); \\ lichunli_hebut@126.com (C.L.) \\ * Correspondence: yfsh@hebut.edu.cn
}

Citation: Zhang, W.; Luo, J.; Sun, T.; $\mathrm{Yu}, \mathrm{F}$; Li, C. The Absorption Performance of Ionic

Liquids-PEG200 Complex Absorbent for VOCs. Energies 2021, 14, 3592.

https://doi.org/10.3390/en14123592

Academic Editor: Diego Luna

Received: 14 May 2021

Accepted: 10 June 2021

Published: 16 June 2021

Publisher's Note: MDPI stays neutral with regard to jurisdictional claims in published maps and institutional affiliations.

Copyright: (c) 2021 by the authors. Licensee MDPI, Basel, Switzerland. This article is an open access article distributed under the terms and conditions of the Creative Commons Attribution (CC BY) license (https:// creativecommons.org/licenses/by/ $4.0 /)$.

\begin{abstract}
A novel complex absorbent composed of polyethylene glycol 200 (PEG200) and ionic liquids (ILs) was prepared for the absorption of volatile organic compounds (VOCs) such as dichloromethane (DCM) and benzene. We prepared complex absorbents composed of [EMIM][Cl], [BMIM][Cl], [HMIM][Cl], [BMIM] $\left[\mathrm{BF}_{4}\right],[\mathrm{BMIM}]\left[\mathrm{PF}_{6}\right],[\mathrm{BMIM}]\left[\mathrm{NTF}_{2}\right]$, and PEG200, respectively, and studied the absorption properties of these six complex absorbents for DCM and benzene. The results show that under the optimized situation, the absorptivity of [HMIM][Cl]-PEG200 complex absorbent for DCM is $85.46 \%$ in the first $5 \mathrm{~min}$, and $87.15 \%$ for benzene. No obvious decay in the absorptivity of [HMIM][Cl]PEG200 for DCM and benzene was observed in five cycles, indicating an impressive regeneration performance. Furthermore, the mechanism of ionic liquid absorption for VOC is explored by thermodynamic analysis and quantum chemical calculations. The theoretical calculation results show that the [HMIM][Cl]-DCM interaction is stronger than the [HMIM][Cl]-benzene interaction, which is consistent with the results of the absorption experiment. Moreover, the strong hydrogen bonds can be formed between both [HMIM][Cl]-DCM and [HMIM][Cl]-benzene.
\end{abstract}

Keywords: ionic liquids; absorption; volatile organic compound; dichloromethane; benzene

\section{Introduction}

Various volatile organic compounds (VOCs) are produced in the petrochemical industry, including benzene, dichloromethane, acetone, and phenol [1,2]. To date, more and more attention has been paid to the treatment of dichloromethane and benzene because they are highly toxic, leading to the risk of human cancer [3-5]. Therefore, the effective method of capturing and processing VOCs is the key to protect the ecological environment, improve human health, and achieve sustainable development [6]. At present, there are two ways to treatment the VOCs: destructive and recyclable techniques [7]. The technologies for destroying VOCs mainly include thermal or catalytic oxidation [8], biodegradation [9], and plasma methods [10]. These technologies convert VOCs into carbon dioxide and water, mainly through physical methods or chemical reactions. The recovery techniques include absorption [7,11], adsorption [12,13], condensation [14], and membrane separation [15,16]. These methods enrich or separate VOCs by physical or chemical methods. Two-stage condensation is often used in industrial processes to recover DCM and benzene. However, the concentration of DCM in the exhaust gas makes it difficult to meet emission standards [17]. Therefore, it is of great significance to find a new method that enables us to efficiently treat dichloromethane and benzene at the same time. Notably, the absorption method has been extensively used due to its simplicity, safety, recyclability, low energy consumption, and good price competitiveness. Besides, it is worth noting that the most important thing during the absorption is to choose the most appropriate absorbent for it. The common solutions used for removing VOC include water, alcohol, and ketone [18,19]. However, these absorbents have plenty of disadvantages such as low absorptivity, poor recyclability, 
high corrosiveness, and tendency to cause secondary pollution. Therefore, it has always been the focus of a great number of researchers to address the problems happening with applying the traditional absorbents for the absorption.

Ionic liquids (ILs) have been widely studied because of their extremely low vapor pressure, adjustable structure, high solubility for organic substances, and excellent thermal stability $[20,21]$. Obviously, ionic liquids with extremely low vapor pressure have lower energy consumption during the separation of solutes and solvents than traditional absorbents with high volatility. In recent years, many studies on the absorption of VOC by ILs have been reported [22,23]. For example, Wu et al. [24] synthesized six conventional ILs and measured the capacity of ILs to absorb DCM at different temperatures and partial pressures. The results showed that 1-butyl-3-methylimidazolium thiocyanate ([BMIM][SCN]) had the highest DCM solubility $\left(1.46 \mathrm{~g} \cdot \mathrm{g}^{-1}, 303.15 \mathrm{~K}, 60 \mathrm{kPa}\right)$ among these ILs, and theoretical calculations prove that the reason for the excellent performance of [BMIM][SCN] is the existence of hydrogen bonds between the anion [SCN] and dichloromethane. Li et al. [25] determined the thermodynamic properties of the absorption process of benzene and acetone in eight ILs in detail. The results show that the anion of the IL plays the most important role in determining the solubility of benzene and acetone in ILs, and increases in the following order: $\left[\mathrm{NTf}_{2}\right]^{-}>\left[\mathrm{PF}_{6}\right]^{-}>\left[\mathrm{BF}_{4}\right]^{-}$. Overall, these studies have confirmed that DCM and benzene have high solubility in ILs, but there were few reports on the dynamic absorption for DCM and benzene by ILs. Moreover, the high viscosity of ILs will lead to slow mass transfer, which is a challenge for large-scale application of ILs in the absorption process. Therefore, the key technology to achieve large-scale VOC treatment and recovery is to find a high-efficiency, cheap, and low-viscosity absorbent $[26,27]$. Until now, the use of ILs to absorb VOC has received extensive attention from researchers, but few studies on the absorption of DCM and benzene by ILs have been reported.

In view of the above discussion, ILs are difficult for wide use as absorbents for VOC absorption because of their high viscosity. In this work, we reduced the viscosity of the IL by adding PEG200 to the IL. Subsequently, to explore the absorption performance of the complex absorbent for mixed gases composed of DCM and benzene, we conducted absorption experiments with DCM and benzene as the mixed gases. The experimental results showed that [HMIM][Cl]-PEG200 was an effective absorber for absorbing a gas mixture consisting of DCM and benzene. In addition, the effects of absorption temperature $(\mathrm{T})$, inlet gas flow rate $(\mathrm{Q})$, inlet gas concentration $\left(\mathrm{C}_{\mathrm{DCM}}, \mathrm{C}_{\mathrm{Benzene}}\right)$, and IL mass fraction on the absorptivity were measured. Finally, to explore the absorption mechanism in the absorption process, the interaction energy between VOC and IL was calculated using Gaussian 09 software. The results show that hydrogen bonds can form between both [HMIM][Cl]-DCM and [HMIM][Cl]-benzene.

\section{Materials and Methods}

\subsection{Materials}

Amounts of 1-ethyl-3-methylimidazolium chloride ([EMIM][Cl]) ( $\geq 99 \%)$, 1-butyl-3methylimidazolium chloride ([BMIM][Cl]) ( $\geq 99 \%)$, 1-hexyl-3-methylimidazolium chloride ([HMIM][Cl]) ( $\geq 99 \%)$, 1-butyl-3-methylimidazolium bis(trifluoromethylsulfonyl)imide $\left([\mathrm{BMIM}]\left[\mathrm{NTf}_{2}\right]\right)(\geq 99 \%)$, 1-butyl-3-methylimidazolium tetrafluoroborate ([BMIM][BF 4 ) ( $\geq 99 \%)$, and 1-butyl-3-methylimidazolium hexafluorophosphate ([BMIM][PF 6$])(\geq 99 \%)$ were purchased from Shanghai Chengjie Chemical Co., Ltd., Shanghai, China. Nitrogen ( $\geq 99.99 \%$ ) was purchased from Wance Gas Co., Ltd., Tianjin, China. DCM, benzene, and polyethylene glycol 200 were purchased from Tianjin Kermel Technology Co., Ltd., Shanghai, China. All chemical reagent purity is analytical purity, no further processing and purification was performed before use.

\subsection{Preparation Method of IL-PEG200 Complex Absorbent}

The [HMIM][Cl]-PEG200 complex absorbent preparation process was as follows. A total of $12 \mathrm{~g}$ of [HMIM][Cl] and $8 \mathrm{~g}$ of PEG200 were mixed in a flask and stirred at ambient 
temperature for an hour until [HMIM][Cl] and PEG200 formed a homogeneous mixture ([HMIM][Cl]-PEG200). The procedure of preparation of [[EMIM][Cl]-PEG200, [BMIM][Cl]-

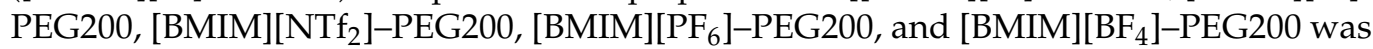
performed using a similar method.

\subsection{Characterization}

The IR spectra of the absorbents were obtained by Bruker Tensor 27 IR spectrometer with 16 scans in the range of 4000 to $400 \mathrm{~cm}^{-1}$. Then, ${ }^{1} \mathrm{H}$ NMR spectra was acquired on a Bruker $\mathrm{AV} 400$ spectrometer in $\mathrm{CDCl}_{3}$. The viscosity of the absorbent was measured by using the rotating viscometer (NDJ-79, Shanghai Changji Geological Instrument Co., Ltd., Shanghai, China.) with different rotors.

\subsection{Absorption Process}

The experimental apparatus is illustrated in Scheme 1. The gaseous mixture of DCM and nitrogen and the gaseous mixture of benzene and nitrogen are obtained by two independent bubblers (3) and enter the gas mixer (5). The mass concentrations of DCM and benzene are adjusted by respective mass flow meters (2), respectively. The temperature of the gas is controlled by the oil bath (4). The gas flow is controlled by the mass flow meters. The mixed gas enters the gas washing bottle filled with absorbent, and the outlet gas is discharged into the atmosphere after passing through the tail gas treatment device. Samples are taken at the inlet and outlet of the gas washing bottle, and their concentrations are analyzed by gas chromatogram. The pipes before and after the absorption bottle are polytetrafluoroethylene pipes. The absorption bottle is preloaded with $40 \mathrm{~g}(43.24 \mathrm{~mL})$ complex absorbent for each test. The diameter of the absorption bottle is $4 \mathrm{~cm}$. In order to simulate the ratio of industrial waste gas, the mass concentration ratio of DCM and benzene is set to $4: 1$. After the absorption experiment, the regeneration of the absorbent is stripped by nitrogen at a temperature of $333.15 \mathrm{~K}$.

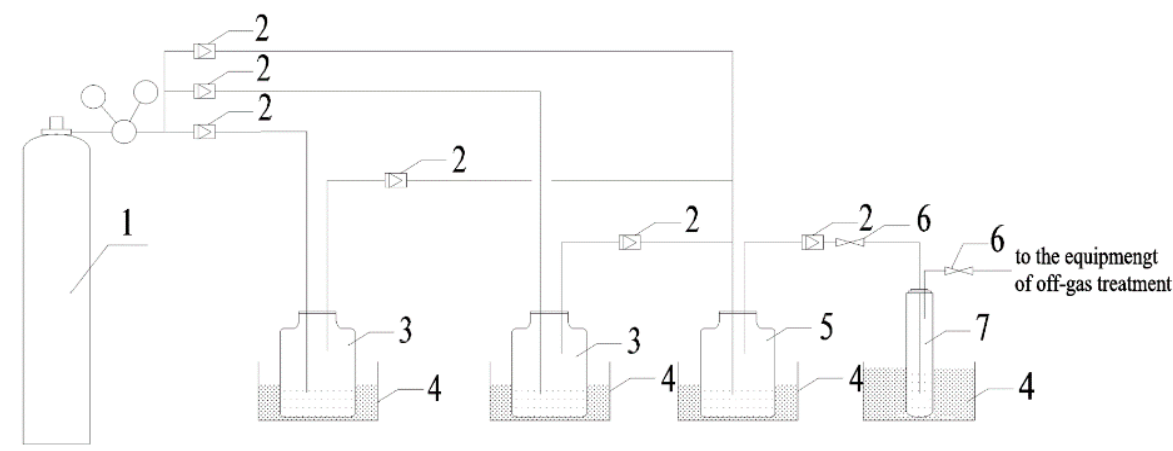

Scheme 1. Absorption experiment device (1-nitrogen bottle, 2-mass flow meters, 3-bubblers, 4 - constant temperature water bath, 5-gas mixer, 6-sampling port, 7-absorption bottle).

\subsection{Analysis of $V O C$}

Absorptivity $(\eta)$ was used to evaluate the absorptivity of IL complex absorbent for DCM and benzene. The absorptivity calculation formula is as follows:

$$
\eta=\frac{C_{g, i}-C_{g, o}}{C_{g, i}} \times 100 \%
$$

where $\eta$ refers to the absorptivity of DCM or benzene in the IL, $C_{g, i}$ refers to the inlet concentration of DCM or benzene $\left(\mathrm{mg} \cdot \mathrm{m}^{-3}\right)$, and $C_{g, o}$ refers to the outlet concentration of DCM or benzene $\left(\mathrm{mg} \cdot \mathrm{m}^{-3}\right)$.

The concentration of DCM and benzene was measured by GC (SP-3420A, CHINA), hydrogen flame detector, KB-5 capillary column, column temperature $358.15 \mathrm{~K}$, sampler 
temperature $423.15 \mathrm{~K}$, and detector temperature $433.15 \mathrm{~K}$. In order to ensure the accuracy of the results, each sample was tested three times and the average value was calculated.

\subsection{The Saturated Absorption Capacity of Absorption}

During the dynamic absorption experiment, the absorbent continued to absorb DCM and benzene, and the total mass of the absorbent continued to increase. When the inlet gas concentration and the outlet gas concentration were almost equal and there was no significant change within half an hour, the absorbent at this time was considered to reach the dynamic absorption equilibrium. At this time, the ratio of the mass of DCM and benzene absorbed by the absorbent to the mass of the absorbent before absorption is recorded as the saturated absorption capacity. The saturated absorption capacity of absorption was experimentally measured when the DCM concentration, the benzene concentration, absorption temperature, inlet gas flow rate, and mass fraction of IL were fixed at $20,000 \mathrm{mg} \cdot \mathrm{m}^{-3}, 5000 \mathrm{mg} \cdot \mathrm{m}^{-3}, 298.15 \mathrm{~K}, 0.036 \mathrm{~m}^{3} \cdot \mathrm{h}^{-1}$, and $60 \%$, respectively.

\subsection{COSMO-SAC Model}

The COSMO for segment activity coefficient (COSMO-SAC) model, derived from the conductor-like screening model (COSMO) [28,29], was first proposed by Lin and Sandler, and is often used to calculate the interaction between molecules and predict the infinite dilution activity coefficient of the solute in the solvent [29-31]. First, the $\sigma$-spectrum is obtained by quantum chemistry calculations, but this process requires a lot of time. In addition, the time required for calculation increases exponentially as the number of atoms in the molecule increases. Therefore, the time required for the calculation is reduced by calculating the $\sigma$-spectra of the anions and cations of the IL separately. Finally, the sigma spectra of IL are obtained by adding the sigma spectra of anions and cations [32,33]. The anions and cations of the IL are drawn by Materials Studio [34]. The optimized anions and cations of the IL are obtained from using the density functional theory with nonlocal VWN-BP functional at the DNP v4.0 basis set [35,36]. After the geometry optimization, the screening charge density $\left(\sigma^{*}\right)$ was calculated by the COSMO model. The surface charge density of standard segment $\sigma_{m}$ was calculated by Equation (2).

$$
\sigma_{m}=\frac{\sum_{n} \sigma_{m}^{*}\left(\frac{r_{n}^{2} r_{e f f}^{2}}{r_{n}^{2}+r_{e f f}^{2}}\right) \exp \left[-f_{\text {decay }}\left(\frac{d_{m n}^{2}}{r_{n}^{2}+r_{\text {eff }}^{2}}\right)\right]}{\sum_{n}\left(\frac{r_{n}^{2} r_{e f f}^{2}}{r_{n}^{2}+r_{\text {eff }}^{2}}\right) \exp \left[-f_{\text {decay }}\left(\frac{d_{m n}^{2}}{r_{n}^{2}+r_{\text {eff }}^{2}}\right)\right]}
$$

In the formula, $r_{\text {eff }}$ is the adjustable parameter, $r_{\text {eff }}^{2}=\sqrt{\frac{a_{\text {eff }}}{\pi}}\left(a_{e f f}=7.50 \AA^{2}\right), r_{n}$ is the average radius of the segment, and $d_{m n}$ is the distance of the segment.

The probability distribution of surface charge density obtained by calculation is also called the sigma profile. The definition of the sigma profile for a single molecule is as follows:

$$
P_{i}=A_{i}(\sigma) / A_{i}=n_{i}(\sigma) / n_{i}
$$

where $A_{i}(\sigma)$ is the surface area with a charge density of value $\sigma$, and $A_{i}$ is the total surface area of species $i$. For a mixture, the $\sigma$-profile is obtained by a weighted average of the $\sigma$-profile of individual components (Equation (4)).

$$
p_{s}(\sigma)=\sum_{i} x_{i} A_{i} p_{i}(\sigma) / \sum_{i} x_{i} A_{i}
$$

Finally, the sigma profiles of the IL and the solute obtained in the thermodynamic model are used to calculate the activity coefficient of the solute $i$ in the solution. The detailed equation is as follows:

$$
\ln \gamma_{i}=n_{i} \sum_{\sigma_{m}} p_{i}\left(\sigma_{m}\right)\left[\ln \Gamma_{\mathcal{S}}\left(\sigma_{m}\right)-\ln \Gamma_{i}\left(\sigma_{m}\right)\right]+\ln \gamma_{i}^{S G}
$$




$$
\begin{aligned}
& \ln \Gamma_{i}\left(\sigma_{m}\right)=-\ln \left\{\sum_{\sigma_{n}} p_{i}\left(\sigma_{n}\right) \Gamma_{i}\left(\sigma_{n}\right) \exp \left[-\Delta W\left(\sigma_{m}, \sigma_{n}\right) / K T\right]\right\} \\
& \ln \Gamma_{s}\left(\sigma_{m}\right)=-\ln \left\{\sum_{\sigma_{n}} p_{s}\left(\sigma_{n}\right) \Gamma_{s}\left(\sigma_{n}\right) \exp \left[-\Delta W\left(\sigma_{m}, \sigma_{n}\right) / K T\right]\right\}
\end{aligned}
$$

where $\Delta W$ refers to the interaction energy between fragments and is presented in detail in original papers (COSMO-SAC(2007) [30], COSMO-SAC(2010) [32], and COSMOSAC(ion)) [37].

$$
\begin{gathered}
\ln \left(\gamma_{i}^{S G}\right)=\ln \left(\frac{\phi_{i}}{x_{i}}\right)+\frac{z}{2} q_{i} \ln \left(\frac{\theta}{\phi_{i}}\right)+l_{i}-\frac{\phi_{i}}{x_{i}} \sum_{j} x_{j} l_{j} \\
\theta_{i}=x_{i} q_{i} / \sum_{j} x_{j} q_{j}, \phi_{i}=x_{i} r_{i} / \sum_{j} x_{j} r_{j} \\
l_{i}=\frac{z}{2}\left[\left(r_{i}-q_{i}\right)-\left(r_{i}-1\right)\right]
\end{gathered}
$$

where $R$ is the universal gas constant, $T$ is the temperature, $x_{i}$ is the mole fraction of component $i, n_{i}$ is the total number of segments in component $i\left(n_{i}=A_{i} / a_{e f f}\right), a_{e f f}$ is the standard surface segment area (empirical parameter) $\left(a_{e f f}=0.075 \mathrm{~nm}^{2}\right), r_{i}$ is the standard volume parameter of component $i, q_{i}$ is the standard area parameter of component $i$, and $z$ is the coordination number $(z=10)$.

\subsection{Quantum Chemistry Calculation}

We carried out density functional theory (DFT) calculations on the binding energy of each system by Gaussian 09 [38]. The molecules (IL, DCM, and benzene) were optimized by B3LYP / 6-311G* basis set and the energy of each system (I-DCM and IL-benzene) was calculated [38-41]. Then, the binding energy of each IL to DCM and benzene was calculated by the following equation:

$$
\Delta E_{A-B}\left(\mathrm{~kJ} \cdot \mathrm{mol}^{-1}\right)=E_{A-B}-\left(E_{A}-E_{B}\right)
$$

where $E_{A}$ is the energy $(\mathrm{eV})$ of a single molecular model, $E_{B}$ is the energy $(\mathrm{eV})$ of adsorbed molecule $B$, and $E_{A-B}$ is the energy (eV) of $A-B$ adsorption system.

\section{Results}

\subsection{Absorbent Screening}

In order to find an absorbent with high absorptivity for DCM and benzene, the absorptivity of complex absorbents containing different ILs were tested (Figure 1). Among them, the mass fraction of IL in the IL-PEG200 complex absorbent is $60 \%$. As shown in Figure 1a, the absorptivities (at $5 \mathrm{~min}$ ) of [EMIM][Cl]-PEG200, [BMIM][Cl]-PEG200, and [HMIM][Cl]PEG200 for DCM were higher than those of other absorbents, and their absorptivities (at $5 \mathrm{~min}$ ) were $82.16 \%, 78.45 \%$, and $72.31 \%$, respectively. Interestingly, the complex absorbents containing anion $[\mathrm{Cl}]^{-}$all showed high absorptivity for DCM, which may be due to the strong affinity of the anion $[\mathrm{Cl}]^{-}$with DCM. Furthermore, the absorption properties of DCM by the complex absorbent containing anion $[\mathrm{Cl}]^{-}$decreased with the increase of the length of the alkyl chain of the cation. The reason may be that as the length of the alkyl chain of the cation increases, the nonpolar increase of the IL was not conducive to the absorption of dichloromethane. In addition, as shown in Figure $1 \mathrm{~b}$, the order of absorptivity (at $5 \mathrm{~min}$ ) of benzene by complex absorbents was [BMIM] $\left.\mathrm{NTf}_{2}\right]-\mathrm{PEG} 200>$ [HMIM] [Cl]-PEG200 $>$ [BMIM] $\left[\mathrm{PF}_{6}\right]-\mathrm{PEG} 200>\left[\mathrm{BMIM}^{2}\left[\mathrm{BF}_{4}\right]-\mathrm{PEG} 200>[\mathrm{BMIM}][\mathrm{Cl}]-\mathrm{PEG} 200>[\mathrm{EMIM}][\mathrm{Cl}]-\right.$ PEG200. Overall, a comprehensive analysis of the results of absorption experiments shows that [HMIM][Cl]-PEG200 has a higher absorption rate for both DCM and benzene. Therefore, the [HMIM][Cl]-PEG200 complex absorbent was selected as the typical complex absorbent in the follow-up work. 

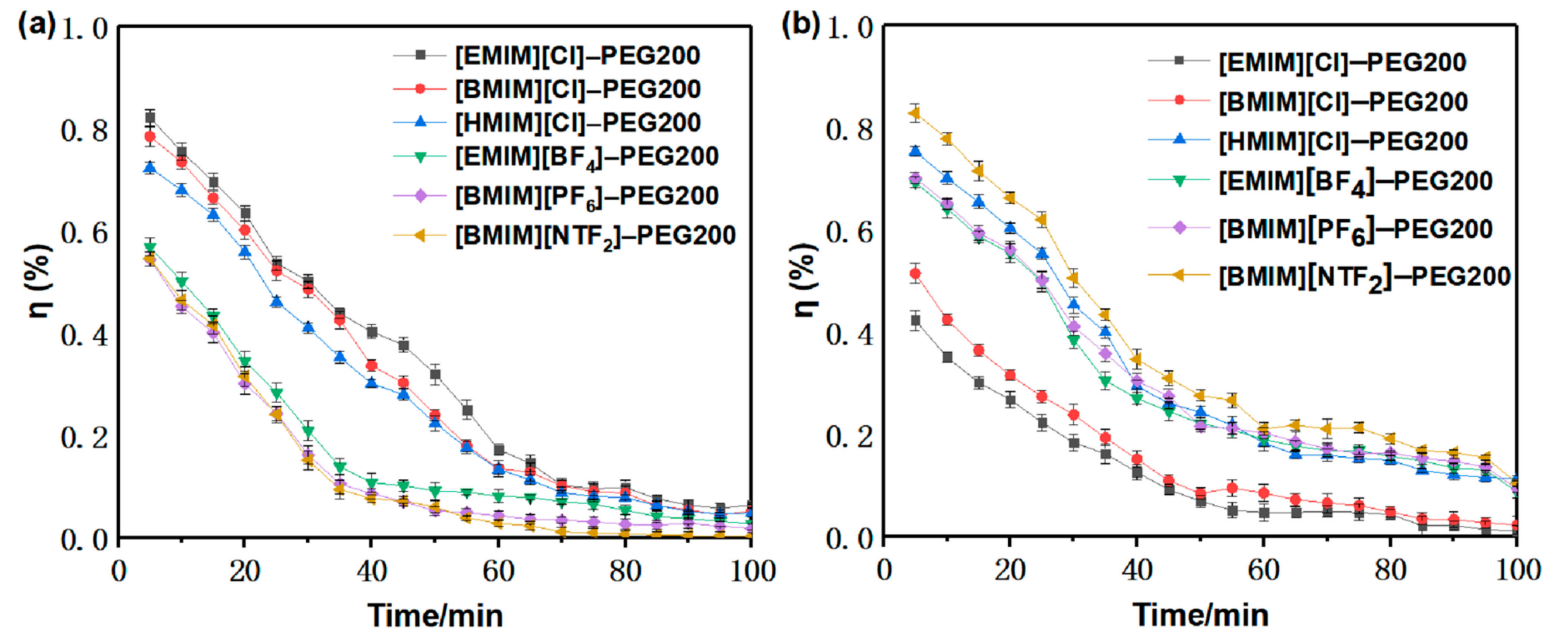

Figure 1. The influence of different complex absorbents on the absorptivity for (a) DCM and (b) benzene $\left(C_{\text {DCM }}=20,000 \mathrm{mg} \cdot \mathrm{m}^{-3}, C_{\text {Benzene }}=5000 \mathrm{mg} \cdot \mathrm{m}^{-3}, \mathrm{Q}=0.036 \mathrm{~m}^{3} \cdot \mathrm{h}^{-1}, 60 \mathrm{wt} \% \mathrm{IL}, \mathrm{T}=298.15 \mathrm{~K}\right)$.

\subsection{Influence of Different Mass Fractions of IL in Absorbent}

The saturated absorption capacity of pure IL for the mixture of DCM and benzene reached $114.97 \mathrm{mg} \cdot \mathrm{g}^{-1}$ (Table 1), and it was far greater than that of PEG200 for the mixed gas. In addition, it could be seen from the experimental results in Figure 2 that the absorption performance for DCM and benzene by pure [HMIM][Cl] was much greater than that of pure PEG200. Therefore, [HMIM] $[\mathrm{Cl}]$ played an important role in absorbing mixed waste gas. The absorptivity of [HMIM][Cl]-PEG200 for DCM and benzene under the different mass fraction of IL in complex absorbent was measured (Figure 2). When the mass fraction of the IL in the complex absorbent dropped from $100 \%$ to $70 \%$, the absorptivity (at $5 \mathrm{~min}$ ) of the complex absorbent for DCM and benzene increased. In addition, the absorptivity (at $5 \mathrm{~min}$ ) of the complex absorbent for DCM and benzene even reached $72.31 \%$ and $75.37 \%$, respectively, when the mass fraction of the IL in the absorbent was $60 \%$. Obviously, diluting the IL with PEG200 reduced the viscosity of the absorbent (Table 2), thus improving the bubble dispersion and allowing the solute to better contact the absorbent. However, when the mass fraction of IL in the complex absorbent was further reduced from $60 \%$ to $50 \%$, the absorptivity (at $5 \mathrm{~min}$ ) of the complex absorbent for DCM and benzene decreased to $36.12 \%$ and $46.87 \%$, respectively. This was because, although PEG200 was mixed with IL to effectively improve the mass transfer efficiency, with the further increase of the content of PEG200, the decrease of IL concentration would lead to a decrease in the dissolution capacity of complex absorbers. In short, the increase in mass transfer efficiency failed to offset the decrease in absorption performance caused by the adverse effect of the decrease in the concentration of IL. Therefore, in the process of absorbing DCM and benzene by the complex absorbent, the optimal mass fraction of the IL in the absorbent was $60 \%$. Thus, in subsequent experiments, the amount of IL was fixed at $60 \%$ of the total mass ( $40 \mathrm{~g}$ ) of the absorbent.

Table 1. Saturation absorption of DCM and benzene mixed gas by absorbent.

\begin{tabular}{cc}
\hline Absorbents & Saturated Absorption (mg. $\mathbf{g}^{\mathbf{- 1}} \mathbf{)}$ \\
\hline$[\mathrm{HMIM}][\mathrm{Cl}]$ & 114.97 \\
PEG200 & 33.21 \\
{$[\mathrm{HMIM}][\mathrm{Cl}]-\mathrm{PEG} 200(60 \mathrm{wt} \%[\mathrm{HMIM}][\mathrm{Cl}])$} & 81.36 \\
\hline
\end{tabular}



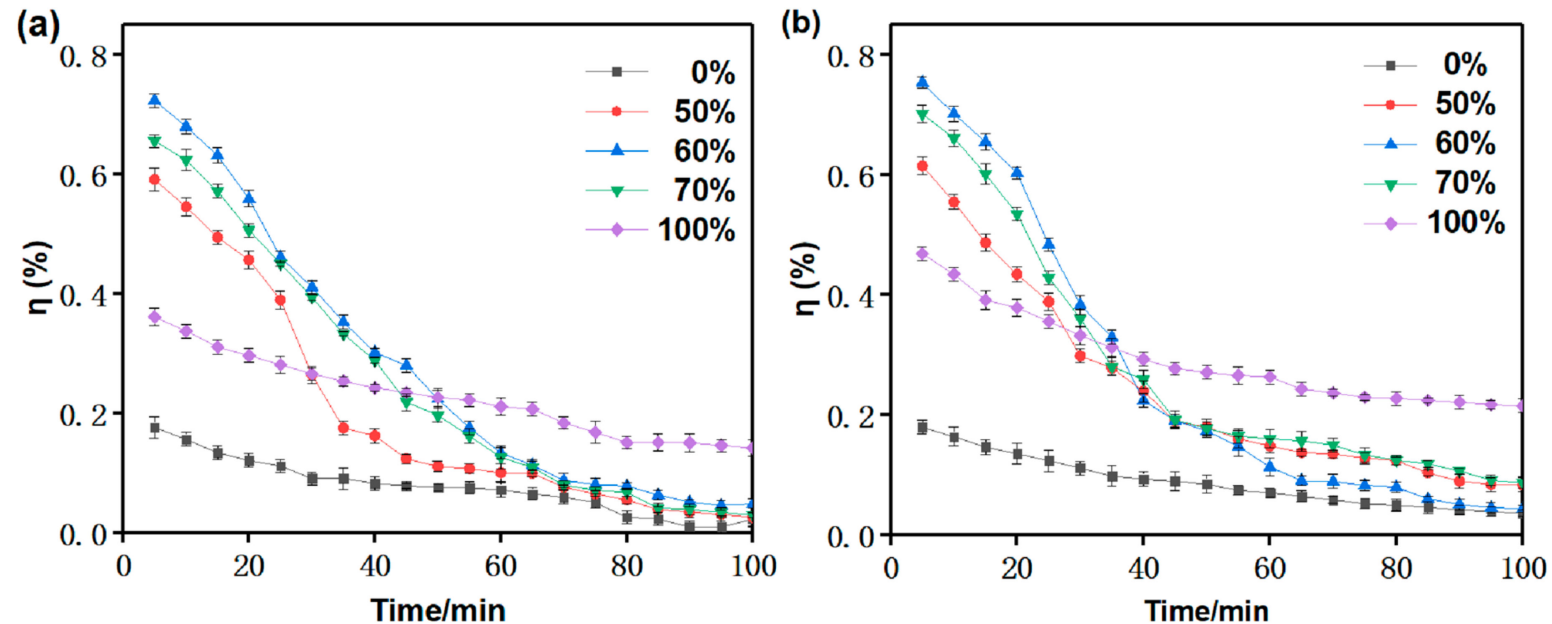

Figure 2. The influence of mass fraction of IL in complex absorbent on the absorptivity for (a) DCM and (b) benzene $\left(C_{\mathrm{DCM}}=20,000 \mathrm{mg} \cdot \mathrm{m}^{-3}, \mathrm{C}_{\text {Benzene }}=5000 \mathrm{mg} \cdot \mathrm{m}^{-3}, \mathrm{Q}=0.036 \mathrm{~m}^{3} \cdot \mathrm{h}^{-1}, \mathrm{~T}=298.15 \mathrm{~K}\right)$.

Table 2. Viscosity of complex absorbent with different mass fractions of IL at $\mathrm{T}=298.15$ to $333.15 \mathrm{~K}$.

\begin{tabular}{cccccccc}
\hline \multicolumn{2}{c}{ Composition (wt\%) } & \multicolumn{7}{c}{ Viscosity (mPa·s) } \\
\hline [HMIM][Cl] & PEG200 & $\mathbf{2 9 8 . 1 5} \mathbf{K}$ & $\mathbf{3 0 3 . 1 5 ~ K}$ & $\mathbf{3 0 8 . 1 5} \mathbf{K}$ & $\mathbf{3 1 3 . 1 5} \mathbf{K}$ & $\mathbf{3 2 3 . 1 5} \mathbf{K}$ & $\mathbf{3 3 3 . 1 5 ~ K}$ \\
\hline 0 & 100 & 36 & 32 & 27 & 24 & 18 & 14 \\
50 & 50 & 180 & 140 & 107 & 88 & 58 & 40 \\
60 & 40 & 288 & 199 & 149 & 115 & 68 & 37 \\
70 & 30 & 421 & 299 & 214 & 158 & 90 & 55 \\
100 & 0 & 580 & 418 & 296 & 218 & 149 & 90 \\
\hline
\end{tabular}

\subsection{Influence of Variable Parameters on VOC Absorptivity in the Complex Absorption}

The effect of the absorption performance $\left(\mathrm{C}_{\mathrm{DCM}}, \mathrm{C}_{\mathrm{Benzene}}, \mathrm{T}\right.$, and $\left.\mathrm{Q}\right)$ of $[\mathrm{HMIM}][\mathrm{Cl}]-$ PEG200 for DCM and benzene at different parameters was investigated.

The absorptivity of [HMIM][Cl]-PEG200 for DCM and benzene at different inlet gas concentrations was explored. As shown in Figure 3, with the increase of inlet gas concentration, there was no significant change in the absorptivity for benzene, but the DCM absorptivity (at $5 \mathrm{~min}$ ) decreased from $72.31 \%$ to $62.53 \%$ when the DCM inlet gas concentration increased from $20,000 \mathrm{mg} \cdot \mathrm{m}^{-3}$ to $50,000 \mathrm{mg} \cdot \mathrm{m}^{-3}$. It is worth noting that, with the prolongation of the experimental time, the absorptivity decreases more slowly at the inlet concentration of $20,000 \mathrm{mg} \cdot \mathrm{m}^{-3}$ and $5000 \mathrm{mg} \cdot \mathrm{m}^{-3}$ for DCM and benzene. Usually, based on the two-layer film theory, the greater difference in concentration between the gas phase and the gas-liquid phase, the greater the driving force for mass transfer. However, the mass transfer efficiency in practical application is limited by the physical properties and contact area of absorbent. Therefore, the increase of inlet gas concentration will lead to the decrease of absorptivity [42]. Moreover, as the experiment time increased, the concentration of DCM and benzene in the absorbent increased, while the concentration difference between the gas phase and the gas-liquid interface decreased. As is known, this concentration difference was the driving force for the diffusion of DCM molecules and benzene molecules. To sum up, the higher the inlet gas concentration, the faster the absorptivity decreases in the absorption process. 

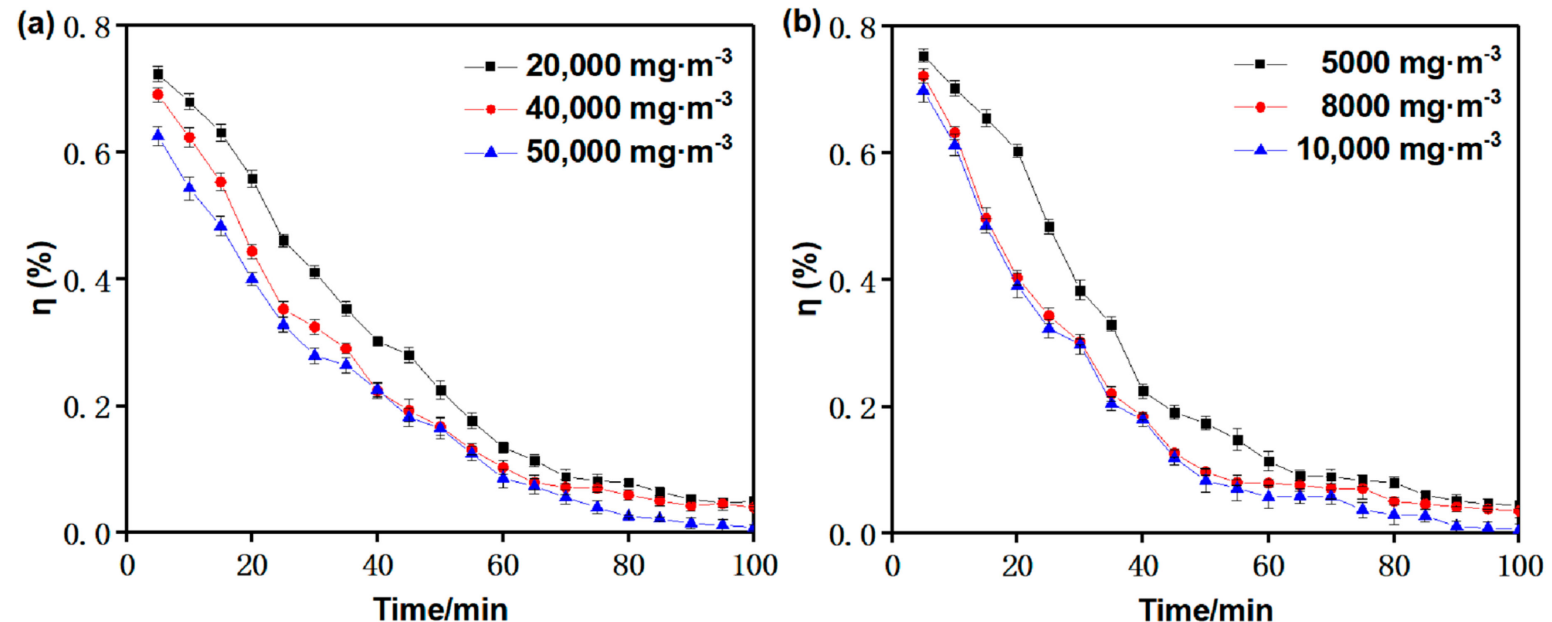

Figure 3. The influence of inlet gas concentration on the absorptivity for (a) DCM and (b) benzene $\left(\mathrm{Q}=0.036 \mathrm{~m}^{3} \cdot \mathrm{h}^{-1}\right.$, $\mathrm{T}=298.15 \mathrm{~K}, 60 \mathrm{wt} \%$ [HMIM][Cl]).

The absorptivity at different absorption temperatures was experimentally measured when the DCM concentration, the benzene concentration, the mass fraction of IL in complex absorbent, and the inlet gas flow rate were fixed at $20,000 \mathrm{mg} \cdot \mathrm{m}^{-3}, 5000 \mathrm{mg} \cdot \mathrm{m}^{-3}, 60 \%$, and $0.036 \mathrm{~m}^{3} \cdot \mathrm{h}^{-1}$, respectively. As shown in Figure 4, when the temperature increases from $298.15 \mathrm{~K}$ to $303.15 \mathrm{~K}$, the absorptivity (at $5 \mathrm{~min}$ ) for DCM and benzene decreases from $72.31 \%$ and $75.37 \%$ to $56.35 \%$ and $59.54 \%$, respectively. As the absorption temperature increases, the Henry's law constants of DCM and benzene in the complex absorbent become larger, indicating that the solubility of DCM and benzene in [HMIM][Cl]-PEG200 decreases. Therefore, the solubility has a significant effect on the absorptivity, causing the absorptivity to decrease with the increase of absorption temperature.
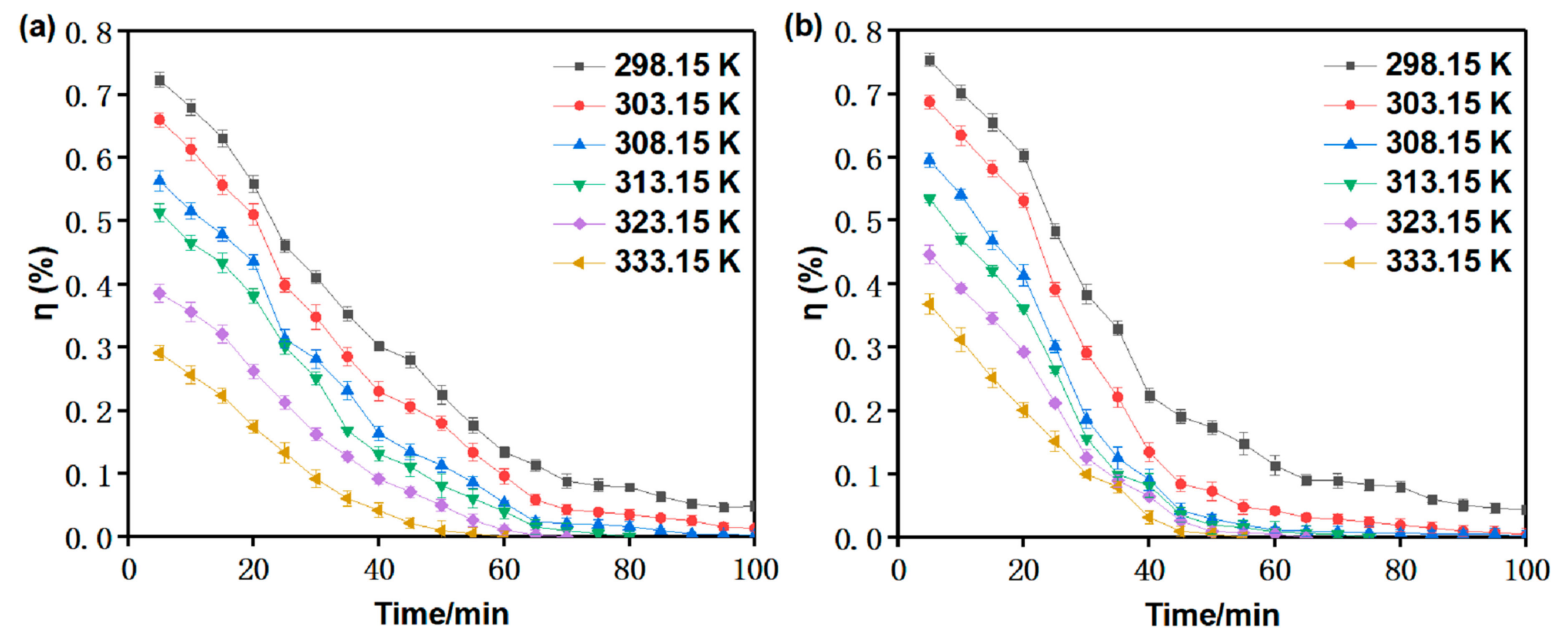

Figure 4. The influence of absorption temperature on the absorptivity for (a) DCM and (b) benzene $\left(C_{D C M}=20,000 \mathrm{mg} \cdot \mathrm{m}^{-3}\right.$, $\left.\mathrm{C}_{\text {Benzene }}=5000 \mathrm{mg} \cdot \mathrm{m}^{-3}, \mathrm{Q}=0.036 \mathrm{~m}^{3} \cdot \mathrm{h}^{-1}, 60 \mathrm{wt} \%[\mathrm{HMIM}][\mathrm{Cl}]\right)$.

As shown in Figure 5, the absorptivity (at $5 \mathrm{~min}$ ) for DCM and benzene increases to varying degrees as the gas flow rate decreases from $0.036 \mathrm{~m}^{3} \cdot \mathrm{h}^{-1}$ to $0.012 \mathrm{~m}^{3} \cdot \mathrm{h}^{-1}$. Among them, the DCM absorptivity (at $5 \mathrm{~min}$ ) increases most obviously, from $72.31 \%$ to $85.46 \%$, while the benzene absorptivity (at $5 \mathrm{~min}$ ) increases from $75.37 \%$ to $87.15 \%$. The reason is that the residence time of the mixed waste gas in the complex absorbent increases when the gas flow rate decreases, which facilitates the contact of the gas and liquid phases. Therefore, with the decrease of inlet flow, the absorptivity of [HMIM][Cl]-PEG200 for DCM and benzene increases under the inlet flow range of $0.012 \mathrm{~m}^{3} \cdot \mathrm{h}^{-1}$ to $0.036 \mathrm{~m}^{3} \cdot \mathrm{h}^{-1}$. 

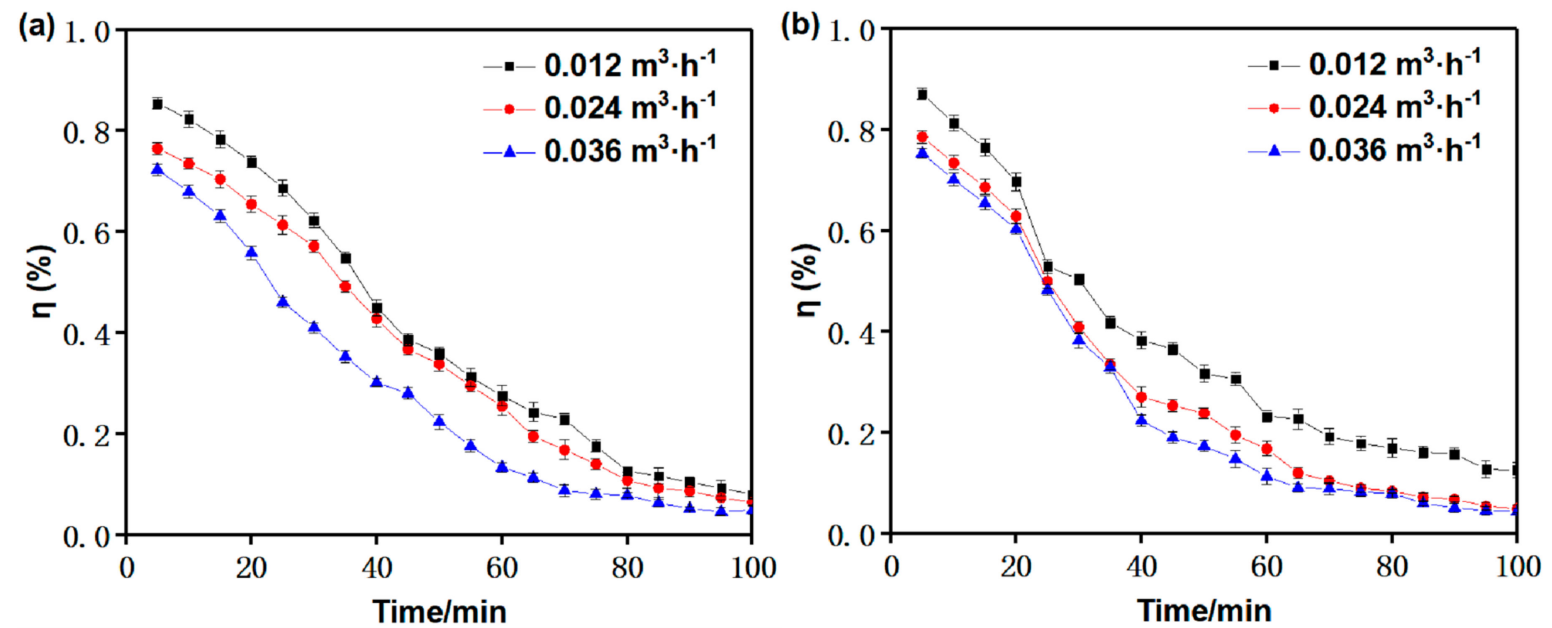

Figure 5. The influence of inlet gas flow on the absorptivity for (a) DCM and (b) benzene $\left(C_{\mathrm{DCM}}=20,000 \mathrm{mg} \cdot \mathrm{m}^{-3}, \mathrm{C}_{\mathrm{Benzene}}\right.$ $=5000 \mathrm{mg} \cdot \mathrm{m}^{-3}, 60 \mathrm{wt} \%$ [HMIM][Cl], T = 298.15 K).

\subsection{Recovery Performance}

The recyclability is an important indicator to evaluate absorbent, and the recycling performance of the [HMIM][Cl]-PEG200 complex absorbent was investigated. As can be seen from Figure 6, after [HMIM][Cl]-PEG200 was repeatedly used five times, the absorptivity for DCM and benzene at 5 min were $85.25 \%$ and $85.95 \%$, respectively, which was only $0.21 \%$ and $1.2 \%$ lower than that of fresh [HMIM][Cl]-PEG200. These results confirm that the complex absorbent had excellent reusable performance. It can be seen from Figure 7 that [HMIM][Cl]-PEG200 is a mixture of [HMIM][Cl] and PEG200, and no new species are produced, indicating that there is no chemical reaction between them. In addition, there are no new peaks in the infrared spectrum of [HMIM][Cl]-PEG200 after absorption and desorption. It can be seen from Figure 8 that after the complex absorbent absorbs DCM and benzene, peaks corresponding to DCM and benzene appear at $5.40 \mathrm{ppm}$ and $7.35 \mathrm{ppm}$. The spectrum of the desorbed complex absorbent is consistent with that of the fresh complex absorbent. In summary, the phenomena in Figures 7 and 8 indicate that [HMIM][Cl]-PEG200 is a physical absorption process for DCM and benzene, and has good stability.

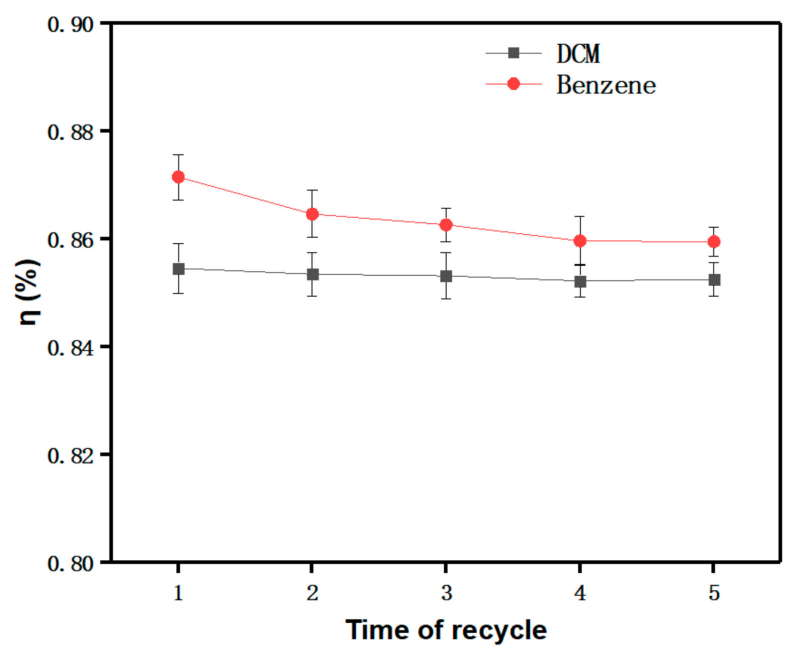

Figure 6. The absorptivity for DCM and benzene at different regeneration times $\left(C_{D C M}=20,000 \mathrm{mg} \cdot \mathrm{m}^{-3}\right.$, $\left.\mathrm{C}_{\text {Benzene }}=5000 \mathrm{mg} \cdot \mathrm{m}^{-3}, \mathrm{Q}=0.036 \mathrm{~m}^{3} \cdot \mathrm{h}^{-1}, \mathrm{~T}=298.15 \mathrm{~K}, 60 \mathrm{wt} \%[\mathrm{HMIM}][\mathrm{Cl}]\right)$. 


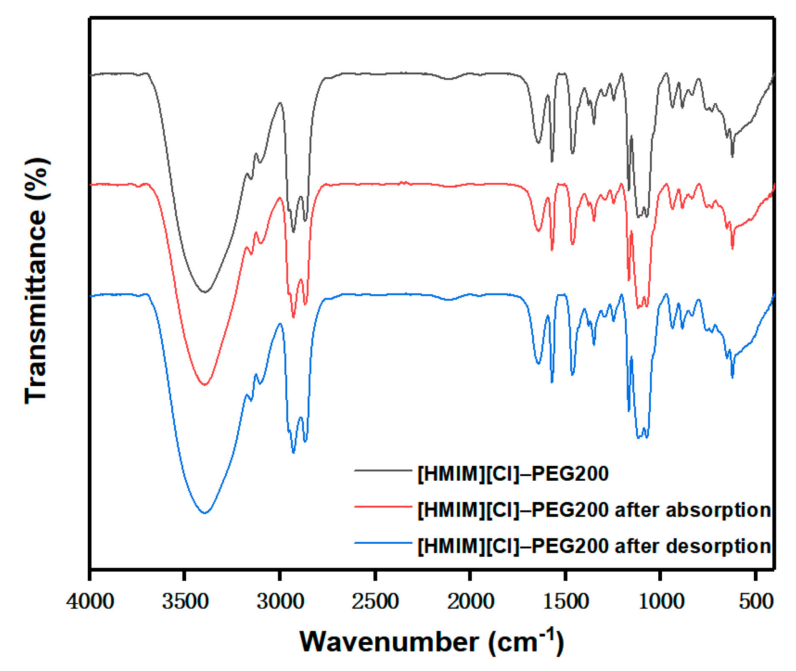

Figure 7. IR spectra of [HMIM][Cl]-PEG200, [HMIM][Cl]-PEG200 after absorption, and [HMIM][Cl]PEG200 after desorption.

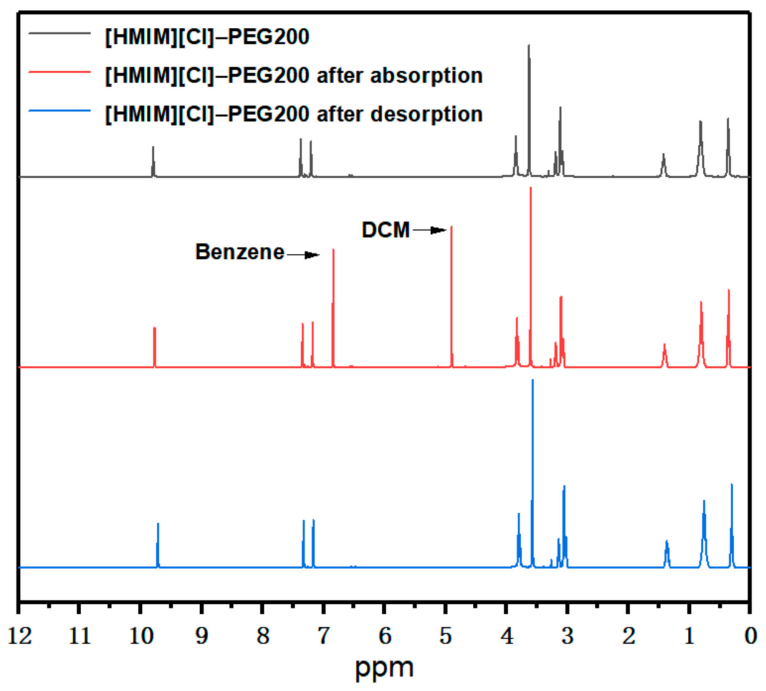

Figure 8. The ${ }^{1} \mathrm{H}-\mathrm{NMR}$ spectra of [HMIM][Cl]-PEG200, [HMIM][Cl]-PEG200 after absorption, and [HMIM][Cl]-PEG200 after desorption.

\subsection{Thermodynamic Calculation and Quantitative Calculation}

In order to explore the absorption mechanism of [HMIM][Cl], DFT theoretical calculation was carried out for IL, DCM, and benzene systems. Firstly, the infinite dilution activity coefficient and Henry's law constant were important thermodynamic parameters of the absorption process [43]. The infinite dilution activity coefficients of DCM or benzene in IL were calculated by the COSMO-SAC model. Moreover, the solubility of DCM or benzene in ILs is a result of the phase equilibrium [44-47]. Therefore, the Henry's constant, Hi(T), is defined as:

$$
H_{i}(T)=\gamma_{i}^{\infty} p_{i}^{s}
$$

In the formula, $H_{i}(\mathrm{kPa})$ refers to Henry's coefficient, $\gamma_{i}^{\infty}$ refers to the activity coefficients at infinite dilution of solute $i$ in the $\mathrm{IL}$, and $p_{i}^{s}(\mathrm{kPa})$ refers to the saturated vapor pressure of DCM or benzene at temperature $T(\mathrm{~K})$.

Table 3 shows that the infinite dilution activity coefficients of DCM in [HMIM][Cl] at different temperatures were all less than 1, which indicates that negative deviations from Raoult's law involve solutes which can be better absorbed by ILs. In addition, as shown in Tables 3 and 4, the Henry's law constants and infinite dilution activity coefficients of DCM 
and benzene increase with the increase of temperature, which indicates that the solubility of DCM and benzene decreases with increasing temperature. Apparently, the absorption of DCM and benzene is physical absorption. In summary, the increase in temperature is not conducive to the absorption of DCM and benzene, which is consistent with the results of the dynamic absorption experiment.

Table 3. Infinite dilution activity coefficients $(\gamma \infty)$ for DCM and benzene in [HMIM][Cl].

\begin{tabular}{|c|c|c|c|c|c|c|}
\hline \multirow{2}{*}{ Absorbent } & \multicolumn{6}{|c|}{$\gamma \infty$} \\
\hline & $303.15 \mathrm{~K}$ & $313.15 \mathrm{~K}$ & $323.15 \mathrm{~K}$ & $333.15 \mathrm{~K}$ & $343.15 \mathrm{~K}$ & $353.15 \mathrm{~K}$ \\
\hline Benzene & 2.0904 & 2.1522 & 2.2090 & 2.2611 & 2.3088 & 2.3521 \\
\hline DCM & 0.0744 & 0.0866 & 0.0997 & 0.1137 & 0.1285 & 0.1440 \\
\hline
\end{tabular}

Table 4. Henry's law constants (Hi) for DCM and benzene in [HMIM][Cl].

\begin{tabular}{ccccccc}
\hline \multirow{2}{*}{ Absorbent } & \multicolumn{7}{c}{$\boldsymbol{H}_{\boldsymbol{i}}$} \\
\cline { 2 - 7 } & $\mathbf{3 0 3 . 1 5} \mathbf{K}$ & $\mathbf{3 1 3 . 1 5} \mathbf{K}$ & $\mathbf{3 2 3 . 1 5} \mathbf{K}$ & $\mathbf{3 3 3 . 1 5} \mathbf{K}$ & $\mathbf{3 4 3 . 1 5} \mathbf{K}$ & $\mathbf{3 5 3 . 1 5} \mathbf{~}$ \\
\hline Benzene & 33.137 & 52.295 & 79.724 & 117.083 & 169.361 & 237.387 \\
DCM & 5.254 & 8.849 & 14.36 & 22.541 & 33.931 & 50.178 \\
\hline
\end{tabular}

The thermodynamic properties of absorbing DCM and benzene in an IL-PEG200 complex absorbent related to the Henry's law constant can be calculated according to the well-known thermodynamic relations [48]:

$$
\begin{gathered}
\Delta G=R T \ln H_{i} \\
\Delta H=R\left[\frac{\partial \ln H_{i}}{\partial(1 / T)}\right]_{p} \\
\Delta S=(\Delta H-\Delta G) / T
\end{gathered}
$$

where $\Delta G, \Delta H$, and $\Delta S$ are the Gibbs free energy, enthalpy, and entropy, respectively.

Table 5 shows that all the enthalpy values were negative, demonstrating that the dissolution of DCM and benzene in [HMIM] [Cl] is exothermic. In addition, the $|\Delta H|$ of DCM and benzene is smaller than the $|\triangle S|$ of DCM and benzene. Therefore, it can be judged that the dissolution of DCM and benzene in [HMIM][Cl] is controlled by entropy. The larger the $\Delta S$ value, the more favorable the absorption process. The partial molar excess enthalpy of the system was calculated by infinite dilution activity coefficient [49-51]. According to the Gibbs-Helmholtz equation, partial molar excess enthalpy $\left(H_{i}^{E, \infty}\right)$ is calculated as follows:

$$
\left[\frac{\partial \ln \gamma_{i}^{\infty}}{\partial(1 / T)}\right]=\frac{H_{i}^{E, \infty}}{R}
$$

where $R$ is the gas constant. The smaller the value of $H_{i}^{E, \infty}$, the greater the interaction force between the solute and the solvent. It can be seen from Table 5 that all $H_{i}^{E, \infty}$ are negative values, which means a strong interaction between the solute and the ionic liquid. Obviously, the $H_{i}^{E, \infty}$ of DCM is much smaller than the $H_{i}^{E, \infty}$ of benzene, indicating that DCM is more

\begin{tabular}{|c|c|c|c|c|}
\hline Absorbent & $\Delta G\left(\mathrm{~kJ} \cdot \mathrm{mol}^{-1}\right)$ & $\Delta H\left(\mathrm{~kJ} \cdot \mathrm{mol}^{-1}\right)$ & $\Delta S\left(\mathrm{~J} \cdot \mathrm{mol}^{-1} \cdot \mathrm{K}^{-1}\right)$ & $H_{i}^{E, \infty}\left(\mathrm{J} \cdot \mathrm{mol}^{-1}\right)$ \\
\hline Benzene & 8.823 & -36.009 & -132.576 & -2299.26 \\
\hline DCM & 4.181 & -41.147 & -149.525 & $-11,978.797$ \\
\hline
\end{tabular}
easily absorbed by [HMIM][Cl], and benzene is easily separated from the solvent.

Table 5. Gibbs energy, enthalpy, entropy, and partial molar excess enthalpy of absorption for DCM and benzene in [HMIM][Cl] at $303.15 \mathrm{~K}$. 


\subsection{Interaction Energy Analysis between IL and Each Absorbed Substance}

The results of quantum chemistry calculations (Figure 9) showed that the strong-toweak order of binding energy of IL-DCM and IL-benzene corresponded to the results of the dynamic absorption experiment. It is worth noting that the binding energy of DCM[HMIM] [Cl] $\left(-34.058 \mathrm{~kJ} \cdot \mathrm{mol}^{-1}\right)$ was far greater than that of benzene-[HMIM][Cl] $(-16.023$ $\mathrm{kJ} \cdot \mathrm{mol}^{-1}$ ), which indicates that $[\mathrm{HMIM}][\mathrm{Cl}]$ had high selectivity for the absorption of DCM. It can be seen from Figure 8 that the shorter the hydrogen bond distance between the ionic liquid and the solute, the better the absorption performance of the ionic liquid for the solute. It is worth noting that, compared with other ionic liquids, [HMIM][Cl] can simultaneously form strong hydrogen bonds with DCM and benzene. In addition, a strong hydrogen bond $(1.67 \AA)$ was formed between the hydrogen atom in the imidazole ring in the cation [HMIM] of IL and the $\mathrm{Cl}$ atom in DCM, and the hydrogen bond was also formed between the anion $\left[\mathrm{Cl}^{-}\right.$and $\mathrm{H}$ atom in DCM (2.02 $\AA$ ), which indicated the strong interaction between [HMIM][Cl] and DCM. There was no obvious hydrogen bond between the cation of [HMIM][Cl] and benzene, but the anion $[\mathrm{Cl}]^{-}$formed a weak hydrogen bond with the hydrogen atom in benzene $(2.16 \AA)$, which indicates that the interaction between [HMIM][Cl] and benzene was weak. The above theoretical calculation shows that $[\mathrm{HMIM}][\mathrm{Cl}]$ had obvious interaction with DCM and benzene, and [HMIM][Cl] was easier to combine with DCM, which indicates that $[\mathrm{HMIM}][\mathrm{Cl}]$ had a stronger absorption effect on DCM.

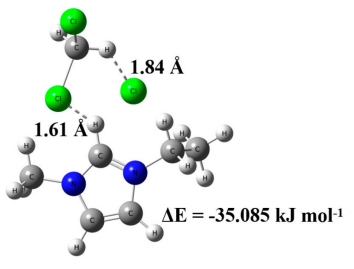

(a) [EMIM][CI]-DCM

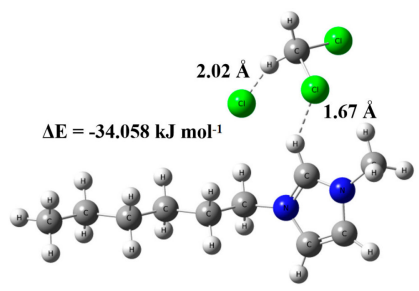

(e) [HMIM][Cl]-DCM

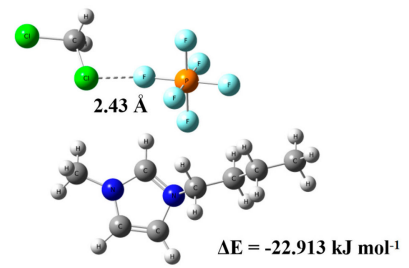

(i) [BMIM] $\left[\mathrm{PF}_{6}\right]-\mathrm{DCM}$

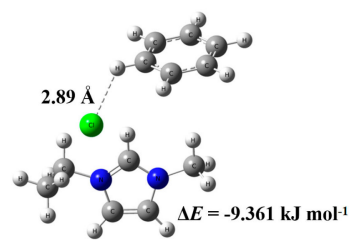

(b) [EMIM][CI]-BENZENE

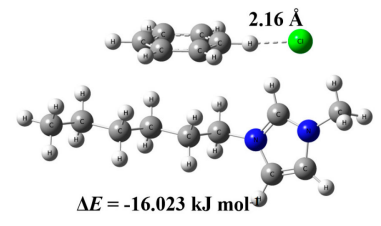

(f) [HMIM]|CI]-BENZENE

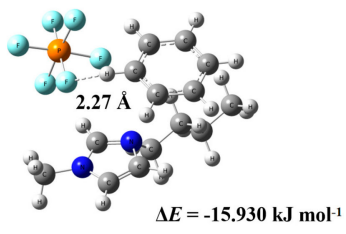

(j) [BMIM] $\left[\mathrm{PF}_{6}\right]$-BENZENE

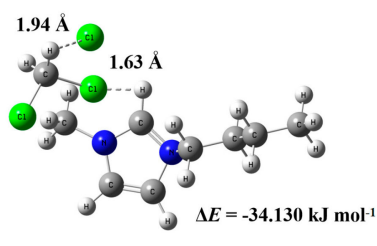

(c) [BMIM][CI]-DCM

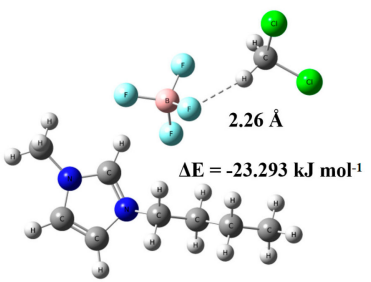

(g) [BMIM] $\left[\mathrm{BF}_{4}\right]-\mathrm{DCM}$

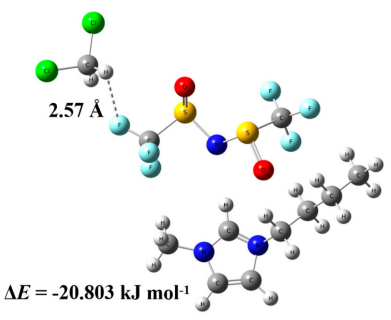

(k) [BMIM] $\left[\mathrm{NTf}_{2}\right]-\mathrm{DCM}$

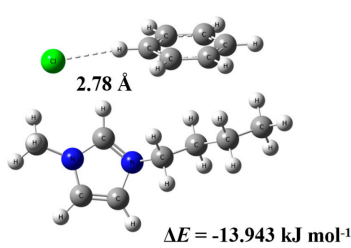

(d) [BMIM][C]]-BENZENE

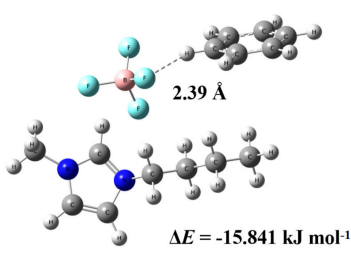

(h) $[\mathrm{BMIM}]\left[\mathrm{BF}_{4}\right]-\mathrm{BENZENE}$

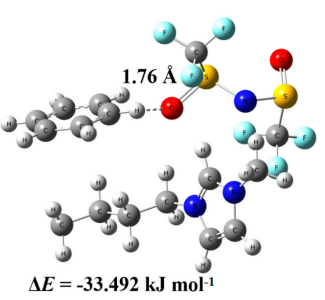

(l) $\left[\right.$ BMIM] $\left[\mathrm{NTf}_{2}\right]-$ BENZENE

Figure 9. The optimized geometric structures obtained by Gaussian 09 software.

\section{Conclusions}

In summary, we designed a variety of IL-PEG200 absorbents and screened out [HMIM][Cl]-PEG200 with high absorptivity for DCM and benzene. The results show that when the concentration of DCM was $20,000 \mathrm{mg} \cdot \mathrm{m}^{-3}$, the concentration of benzene was $5000 \mathrm{mg} \cdot \mathrm{m}^{-3}$, the flow rate of the inlet gas (Q) was $0.036 \mathrm{~m}^{3} \cdot \mathrm{h}^{-1}$, and the absorption temperature was $298.15 \mathrm{~K}$, the absorptivities of $40 \mathrm{~g}$ [HMIM][Cl]-PEG200 with $60 \%$ mass 
concentration of [HMIM][Cl] for DCM and benzene at $5 \mathrm{~min}$ were $85.46 \%$ and $87.15 \%$, respectively. In addition, the [HMIM][Cl]-PEG200 complex absorbent was repeatedly used for five times without a noticeable drop in absorptivity, which verifies the feasibility of recovery and utilization of the complex absorbent. Partial molar excess enthalpy and theoretical calculations show that the interaction of [HMIM][Cl]-DCM is stronger than that of [HMIM][Cl]-benzene, which proves that [HMIM][Cl] absorbs dichloromethane more easily than benzene. Among them, there are strong hydrogen bonds between [HMIM][Cl]DCM and [HMIM][Cl]-benzene, which further proves that the [HMIM][Cl]-PEG200 was an effective absorber for absorbing a gas mixture consisting of DCM and benzene. This work provides a new idea for the design and research of new absorbents containing IL.

Author Contributions: Author research approach and paper frame, W.Z. and J.L.; methodology, T.S.; formal analysis, J.L.; investigation, J.L.; data curation, J.L.; writing-original draft preparation, W.Z.; writing-review and editing, F.Y.; visualization, F.Y.; supervision, C.L. All authors have read and agreed to the published version of the manuscript.

Funding: This work was supported by the Colleges and Universities in Hebei Province Science and Technology Research Project (ZD2015118) and the State Key Laboratory of Fine Chemicals (KF 1909).

Institutional Review Board Statement: Not applicable.

Informed Consent Statement: Not applicable.

Data Availability Statement: Not applicable.

Acknowledgments: The authors would like to acknowledge Hebei University of Technology for providing the support and necessary facilities to conduct the research work.

Conflicts of Interest: The authors declare no conflict of interest.

\section{References}

1. Fang, P.; Tang, Z.-J.; Chen, X.-B.; Tang, Z.-X.; Chen, D.-S.; Huang, J.-H.; Zeng, W.-H.; Cen, C.-P. Experimental study on the absorption of toluene from exhaust gas by paraffin/surfactant/water emulsion. J. Chem. 2016, 2016, 1-9. [CrossRef]

2. Castillo, A.-S.R.; Biard, P.-F.; Guiheneuf, S.; Paquin, L.; Amrane, A.; Couvert, A. Assessment of VOC absorption in hydrophobic ionic liquids: Measurement of partition and diffusion coefficients and simulation of a packed column. Chem. Eng. J. (Amst. Neth.) 2019, 360, 1416-1426.

3. Kampa, M.; Castanas, E.J.E.P. Human health effects of air pollution. Environ. Pollut. (Oxford UK) 2008, 151, 362-367. [CrossRef]

4. Bin Babar, Z.; Shareefdeen, Z. Management and control of air emissions from electronic industries. Clean Technol. Environ. Policy 2014, 16, 69-77. [CrossRef]

5. Karimi, B.; Meyer, C.; Gilbert, D.; Bernard, N. Air pollution below WHO levels decreases by $40 \%$ the links of terrestrial microbial networks. Environ. Chem. Lett. 2016, 14, 467-475. [CrossRef]

6. Yu, G.; Mu, M.; Li, J.; Wu, B.; Xu, R.; Liu, N.; Chen, B.; Dai, C. Imidazolium-based ionic liquids introduced into pi-electron donors: Highly efficient toluene capture. ACS Sustain. Chem. Eng. 2020, 8, 9058-9069. [CrossRef]

7. Wang, W.; Ma, X.; Grimes, S.; Cai, H.; Meng, Z. Study on the absorbability, regeneration characteristics and thermal stability of ionic liquids for VOCs removal. Chem. Eng. J. (Amst. Neth.) 2017, 328, 353-359. [CrossRef]

8. Salvador, S.; Commandré, J.; Kara, Y. Thermal recuperative incineration of VOCs: CFD modelling and experimental validation. Appl. Therm. Eng. 2006, 26, 2355-2366. [CrossRef]

9. Mohseni, M.; Allen, D.G. Biofiltration of mixtures of hydrophilic and hydrophobic volatile organic compounds. Chem. Eng. Sci. 2000, 55, 1545-1558. [CrossRef]

10. Satoh, K.; Matsuzawa, T.; Itoh, H. Decomposition of benzene in a corona discharge at atmospheric pressure. Thin Solid Films 2008, 516, 4423-4429. [CrossRef]

11. Ma, X.; Wu, M.; Liu, S.; Huang, J.; Sun, B.; Zhou, Y.; Zhu, Q.; Lu, H. Concentration control of volatile organic compounds by ionic liquid absorption and desorption. Chin. J. Chem. Eng. 2019, 27, 2383-2389. [CrossRef]

12. Chen, J.; Li, G.; He, Z.; An, T. Adsorption and degradation of model volatile organic compounds by a combined titaniamontmorillonite-silica photocatalyst. J. Hazard. Mater. 2011, 190, 416-423. [CrossRef]

13. Goss, K.U.; Eisenreich, S.J. Adsorption of VOCs from the gas phase to different minerals and a mineral mixture. Environ. Sci. Technol. 1996, 30, 2135-2142. [CrossRef]

14. Hamad, A.; Fayed, M.E. Simulation-aided optimization of volatile organic compounds recovery using condensation. Chem. Eng. Res. Des. 2004, 82, 895-906. [CrossRef]

15. Modelski, S.; Kołtuniewicz, A.; Witek-Krowiak, A. Kinetics of VOC absorption using capillary membrane contactor. Chem. Eng. J. (Amst. Neth.) 2011, 168, 1016-1023. [CrossRef] 
16. Parmar, G.R.; Rao, N.N. Emerging control technologies for volatile organic compounds. Crit. Rev. Environ. Sci. Technol. 2009, 39, 41-78. [CrossRef]

17. Li, Y.; Zhang, H.; Yan, K.; Shang, Z.; Zou, B.; Jiang, S. Research progress of the treatment of waste gas containing chlorinated volatile organic compounds. Mod. Chem. Ind. 2016, 36, 46-49.

18. Biard, P.-F.; Couvert, A. Overview of mass transfer enhancement factor determination for acidic and basic compounds absorption in water. Chem. Eng. J. (Amst. Neth.) 2013, 222, 444-453. [CrossRef]

19. Noorain, R.; Kindaichi, T.; Ozaki, N.; Aoi, Y.; Ohashi, A. Biogas purification performance of new water scrubber packed with sponge carriers. J. Cleaner Prod. 2019, 214, 103-111. [CrossRef]

20. Welton, T.J.C. Room-Temperature Ionic Liquids. Solvents for Synthesis and Catalysis. Chem. Rev. 1999, 99, 2071-2084. [CrossRef]

21. Wilkes, J.S. A short history of ionic liquids-From molten salts to neoteric solvents. Green Chem. 2002, 4, 73-80. [CrossRef]

22. Jiang, Y.; Huang, S.; Lei, Z.; Xu, R. Removal of methyl ethyl ketone and sec-butanol from hydrogen by absorption with ionic liquids. Ind. Eng. Chem. Res. 2020, 59, 14476-14484. [CrossRef]

23. Lei, Z.; Gao, H.; Yu, G.; Jiang, Y. Capturing volatile ester compounds from gas mixture with ionic liquids. J. Mol. Liq. 2019, 281, 517-527. [CrossRef]

24. Wenliang, W.U.; Tao, L.I.; Gao, H.; Shang, D.; Wenhui, T.U.; Wang, B.; Zhang, X. Efficient absorption of dichloromethane using imidazolium based ionic liquids. Chin. J. Process Eng. 2019, 19, 173-180.

25. Li, C.-H.; Gao, K.-X.; Meng, Y.-N.; Wu, X.-K.; Zhang, F.; Wang, Z.-X. Solution thermodynamics of imidazolium-based ionic liquids and volatile organic compounds: Benzene and acetone. J. Chem. Eng. Data 2015, 60, 1600-1607. [CrossRef]

26. Quijano, G.; Couvert, A.; Amrane, A.; Darracq, G.; Couriol, C.; Le Cloirec, P.; Paquin, L.; Carrie, D. Absorption and biodegradation of hydrophobic volatile organic compounds in ionic liquids. Water Air Soil Pollut. 2013, 224, 1528. [CrossRef]

27. Wei, S.-M.; Hu, J.-M.; Wang, X.-D.; Long, C.; Zhang, F.; Zhang, Z.-B. Characterization of absorption performance for gaseous acetone with ionic liquid solutions. Chem. Eng. Technol. 2019, 42, 2658-2665. [CrossRef]

28. Lin, S.T.; Chang, J.; Wang, S.; Goddard, W.A.; Sandler, S.I. Prediction of vapor pressures and enthalpies of vaporization using a COSMO solvation model. J. Phys. Chem. A 2003, 108, 7429-7439. [CrossRef]

29. Lin, S.T.; Sandler, S.I. A priori phase equilibrium prediction from a segment contribution solvation model. Ind. Eng. Chem. Res. 2002, 41, 899-913. [CrossRef]

30. Wang, S.; Sandler, S.I.; Chen, C.-C. Refinement of COSMO-SAC and the applications. Ind. Eng. Chem. Res. 2007, 46, 7275-7288. [CrossRef]

31. Lin, S.T.; Sandler, S.I. Infinite dilution activity coefficients from ab initio solvation calculations. AIChE J. 1999, 45, 2606-2618. [CrossRef]

32. Hsieh, C.-M.; Sandler, S.I.; Lin, S.-T. Improvements of COSMO-SAC for vapor-liquid and liquid-liquid equilibrium predictions. Fluid Phase Equilib. 2010, 297, 90-97. [CrossRef]

33. Fang, J.; Zhao, R.; Su, W.; Li, C.; Liu, J.; Li, B. A molecular design method based on the COSMO-SAC model for solvent selection in ionic liquid extractive distillation. AIChE J. 2016, 62, 2853-2869. [CrossRef]

34. DMol3. Materials Studio; Accelrys Software Inc.: San Diego, CA, USA, 2009.

35. Mullins, E.; Oldland, R.; Liu, Y.A.; Wang, S.; Sandler, S.I.; Chen, C.-C.; Zwolak, M.; Seavey, K.C. Sigma-profile database for using COSMO-based thermodynamic methods. Ind. Eng. Chem. Res. 2006, 45, 4389-4415. [CrossRef]

36. Delley, B. The conductor-like screening model for polymers and surfaces. Mol. Simul. 2006, 32, 117-123. [CrossRef]

37. Hsieh, M.-T.; Lin, S.-T. A predictive model for the excess gibbs free energy of fully dissociated electrolyte solutions. AIChE J. 2011, 57, 1061-1074. [CrossRef]

38. Frisch, M.J.; Trucks, G.W.; Schlegel, H.B.; Scuseria, G.E.; Robb, M.A.; Cheeseman, J.R.; Scalmani, G.; Barone, V.; Mennucci, B.; Petersson, G.A. Gaussian 09 Revision D; Gaussian Inc.: Wallingford, CT, USA, 2009.

39. Boys, S.F.; Bernardi, F.J.M.P. The calculation of small molecular interactions by the differences of separate total energies. Mol. Phys. 2002, 19, 553-566. [CrossRef]

40. Becke, A.D. Density-functional thermochemistry. III. The role of exact exchange. J. Chem. Phys. 1998, 98, 5648-5652. [CrossRef]

41. Lee, C.; Yang, W.; Parr, R.G. Condensed matter. Development of the Colle-Salvetti correlation-energy into a function of the electron density. Phys. Rev. B 1988, 37, 785-789. [CrossRef] [PubMed]

42. Das, T.R.; Bandopadhyay, A.; Parthasarathy, R.; Kumar, R. Gas_Liquid interfacial area in stirred vessels: The effect of an immiscible liquid phase. Chem. Eng. Sci. 1985, 40, 209-214. [CrossRef]

43. Gonzalez-Miquel, M.; Palomar, J.; Rodriguez, F. Selection of ionic liquids for enhancing the gas solubility of volatile organic compounds. J. Phys. Chem. B 2013, 117, 296-306. [CrossRef]

44. Santiago, R.; Lemus, J.; Xiao Outomuro, A.; Bedia, J.; Palomar, J. Assessment of ionic liquids as H2S physical absorbents by thermodynamic and kinetic analysis based on process simulation. Sep. Purif. Technol. 2020, 233, 116050. [CrossRef]

45. Jaschik, M.; Piech, D.; Warmuzinski, K.; Jaschik, J. Prediction of gas solubility in ionic liquids using the COSMO-SAC model. Chem. Process Eng. Inz. Chem. Proces. 2017, 38, 19-30. [CrossRef]

46. Yu, G.; Dai, C.; Gao, H.; Zhu, R.; Du, X.; Lei, Z. Capturing condensable gases with ionic liquids. Ind. Eng. Chem. Res. 2018, 57, 12202-12214. [CrossRef]

47. Li, C.; Wu, X.; Wang, Z.; Zhang, F.; Zhang, Z. Thermodynamic study on absorption of low-pressure benzene vapor in imidazoliumbased ionic liquids. J. Nanjing Univ. Nat. Sci. 2015, 51, 700-706. 
48. Zhang, S.J.; Yuan, X.L.; Chen, Y.H.; Zhang, X.P. Solubilities of $\mathrm{CO}_{2}$ in 1-butyl-3-methylimidazolium hexafluorophosphate and 1,1,3,3-tetramethylguanidium lactate at elevated pressures. J. Chem. Eng. Data 2005, 50, 1582-1585. [CrossRef]

49. Zheng, D.; Dong, L.; Wu, X. New approach for absorbent species selection with excess gibbs function. Ind. Eng. Chem. Res. 2013, 52, 9480-9489. [CrossRef]

50. Kato, R.; Gmehling, J. Systems with ionic liquids: Measurement of VLE and gamma(infinity) data and prediction of their thermodynamic behavior using original UNIFAC, mod. UNIFAC(Do) and COSMO-RS(O1). J. Chem. Thermodyn. 2005, 37, 603-619. [CrossRef]

51. Li, Y.; Wang, L.-S.; Feng, Y.-X.; Zhang, C.-Y. Activity coefficients of organic solutes at infinite dilution in ionic liquids. 1. 1-Hexyl3-methylimidazolium hexafluorophosphate and 1-Octyl-3-methylimidazolium hexafluorophosphate and their application to alkane/aromatic and aromatic/aromatic hydrocarbon separation. Ind. Eng. Chem. Res. 2011, 50, 10755-10764. 